\title{
Postoperative Noninvasive Ventilation
}

\author{
Samir Jaber, M.D., Ph.D., ${ }^{*}$ Gerald Chanques, M.D., † Boris Jung, M.D.†
}

$\mathbf{P}$ OSTOPERATIVE hypoxemia and/or acute respiratory failure (ARF) mainly develop after abdominal and/or thoracic surgery. ${ }^{1}$ Anesthesia, postoperative pain, and surgery will induce respiratory modifications: hypoxemia, decrease in pulmonary volume, and atelectasis ${ }^{1}$ associated with a restrictive syndrome and a diaphragm dysfunction. ${ }^{2}$ These modifications of the respiratory function occur early after surgery and are more often transient and could lead to ARF. The clinical result (severity of the ARF) is the product of perioperative-related ventilatory impairment and severity of the preoperative pulmonary condition. Maintenance of adequate oxygenation in the postoperative period is of major importance, especially when pulmonary complications such as ARF occur. Although invasive endotracheal mechanical ventilation has remained the cornerstone of ventilatory strategy for many years for severe ARF, several studies have shown that mortality associated with pulmonary disease is largely related to complications of postoperative reintubation and mechanical ventilation. Therefore, major objectives for anesthesiologists are first to prevent the occurrence of postoperative complications and second to ensure oxygen administration and carbon dioxide removal while avoiding intubation if ARF occurs. Noninvasive ventilation (NIV) does not require an artificial airway (endotracheal tube or tracheotomy), and its use is well established to prevent ARF occurrence (prophylactic treatment) or to

* Professor and Chairman, $\dagger$ Assistant Professor of Anesthesiology and Critical Care, Anesthesia and Critical Care Department B, Université Montpellier 1, Saint Eloi Teaching Hospital, Equipe Soutenue par la Région et l'Institut National de la Santé et de la Recherche Médicale 25, Centre Hospitalier Universitaire Montpellier.

Address correspondence to Dr. Jaber: Unité de Réanimation et Transplantation, Service d'Anesthésie-Réanimation B, Centre Hospitalier Saint Eloi, 80 Avenue Augustin Fliche, 34295 Montpellier Cedex 5, France. s-jaber@chu-montpellier.fr. This article may be treat ARF to avoid reintubation (curative treatment) (fig. 1). Studies show that patient-related risk factors, such as chronic obstructive pulmonary disease, age older than 60 yr, American Society of Anesthesiologists class of II or higher, obesity, functional dependence, and congestive heart failure, increase the risk for postoperative pulmonary complications. ${ }^{1-4}$ Pulmonary conditions are a key problem for patients who require high-risk surgery for ventilatory function. Then postoperative NIV should be beneficial to these patients at high risk, especially after “aggressive" surgery.

Rationale for postoperative NIV use is the same as the postextubation NIV use ${ }^{5}$ plus the specificities due to the respiratory modifications induced by surgery and anesthesia. Postoperative NIV improves gas exchange, decreases work of breathing, and reduces atelectasis.

The aims of this article are (1) to review the main respiratory modifications induced by surgery and anesthesia, which justify postoperative NIV use, (2) to offer some recommendations to safely apply postoperative NIV, and (3) to present the results obtained with preventive and curative NIV in a surgical context.

\section{Epidemiology}

The efficacy of NIV was first demonstrated for the treatment of patients with acute exacerbations of chronic obstructive pulmonary disease, ${ }^{6}$ followed by a broader use for other kinds of ARF of various etiologies including acute cardiogenic pulmonary edema after solid organ transplant and in immunosuppressed hematology patients. ${ }^{6}$ NIV therapy is increasingly popular for the treatment of the fore cited ARF and for new indications such as improvement of preoxygenation before intubation ${ }^{7,8}$ and postoperative ARF. ${ }^{9-11}$ This widening of indications has been accompanied by the improvement and development of ventilation techniques led by physicians and manufacturers. In 2009, the NIV use in the postoperative period is difficult to estimate, but $69 \%$ of French intensivists declared that they use it for first-line treatment of postoperative ARF and 54\% to treat postoperative atelectasis. ${ }^{12}$ More recently, some authors have reported the feasibility and safety of NIV use in the recovery room after various types of surgery. ${ }^{13}$ 


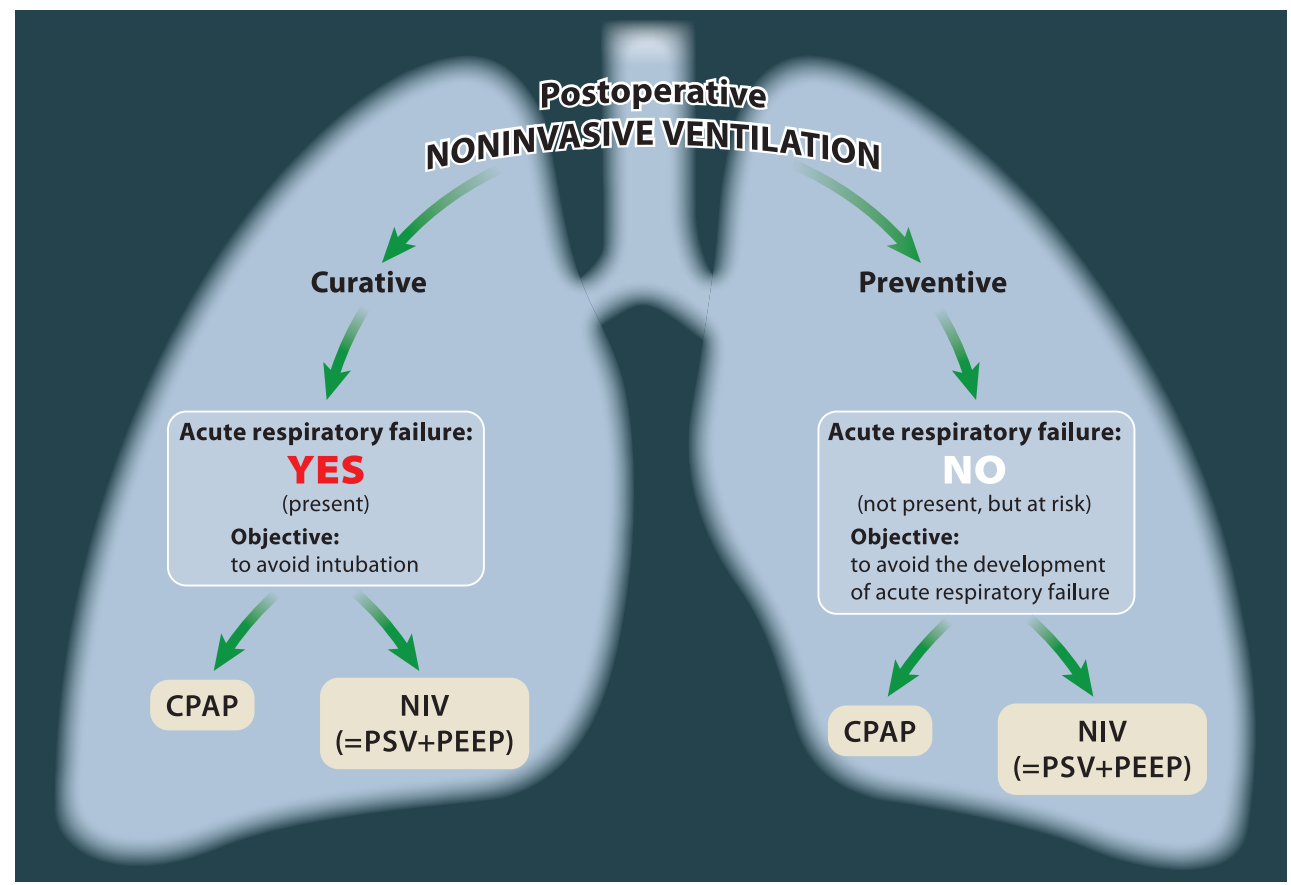

Fig. 1. The two main strategy approaches for applying postoperative noninvasive ventilation (NIV). CPAP = continuous positive airway pressure; PSV = pressure support ventilation; PEEP = positive end expiratory pressure.

\section{Surgery and Anesthesia-induced Respiratory Modifications and Rationale for Postoperative NIV Use}

Major changes in respiratory function occur in all patients after thoracic and abdominal surgery because of anesthetic and surgical consequences (more so as the site of the surgery approaches the diaphragm). Anesthetic decreases muscle tone that increases lung retractile forces and thus contributes to atelectasis development. ${ }^{2}$ Surgery disrupts abdominal, thoracic, and diaphragmatic muscles forces, reduces phrenic output, and induces pain. Taken together, these changes alter the ventilation/perfusion ratio that leads to hypoxemia. These early and transitory modifications of respiratory function may lead to respiratory failure affecting the "pump" function (respiratory muscles) and the "exchange" function (lungs). ${ }^{1}$ Moreover, perioperative-related modifications of the ventilatory system and hypoxemia that were frequently observed in the early postoperative period may be aggravated by other factors, such as excessive perioperative vascular loading, ${ }^{14}$ transfusion-related acute lung injury, inflammation, sepsis, and aspiration.

Clinical arguments in favor of postoperative NIV are the same as those for using NIV in postextubation period ${ }^{5}$ as well as for the respiratory modifications caused by surgery and anesthesia. NIV should supply pump function and improves gas exchange. The main respiratory modifications are maximum in the first hours after surgery and generally regress after 1-2 weeks. ${ }^{1,2}$ The expected benefit of NIV would be to partially compensate for the affected respiratory function by reducing the work of breathing, by improving alveolar ventilation associated with increased gas exchange, reducing left ventricular afterload with increase of cardiac output, and by reducing atelectasis (fig. 2).

\section{Definitions and Principles of the Two Main NIV Techniques: Continuous Positive Airway Pressure (CPAP) and Bilevel Positive Airway Pressure (BIPAP) (= Pressure Support Ventilation [PSV] + Positive End Expiratory Pressure [PEEP])}

NIV delivering positive pressure refers to techniques that permitted ventilatory support to patients without an endotracheal airway, that is, using nasal, facial, or helmet interfaces. Two types of NIV are commonly used: (1) CPAP is a method that delivers noninvasively constant positive airway pressure during both inspiration and expiration, either by use of a flow generator with a high pressure gas source or by use of a portable compressor to spontaneously breathing patients. When CPAP is applied with positive inspiratory PSV, it is referred to as PEEP (in fact CPAP and PEEP are the same entity in clinical application) and (2) BIPAP refers to the association of PSV + PEEP. Definitions and taxonomy of noninvasive ventilatory assist techniques are often confused. NIV is often assimilated to a noninvasive delivered BIPAP (i.e., PSV + PEEP) technique that delivered two positive airway pressures. In fact, NIV includes PSV + PEEP and $\mathrm{CPAP}$, in which the later delivered only one positive airway pressure.

The underlying mechanism by which CPAP exerts its effects is to increase intrathoracic pressure. This way, CPAP prevents airway and alveolar collapse, prevents atelectasis, maintains functional residual capacity, and reduces left ventricular afterload with increase in cardiac output. Moreover, CPAP also permitted to decrease work of breathing by counterbalancing the inspiratory threshold load imposed by intrinsic PEEP in some patients (i.e., chronic obstructive pul- 


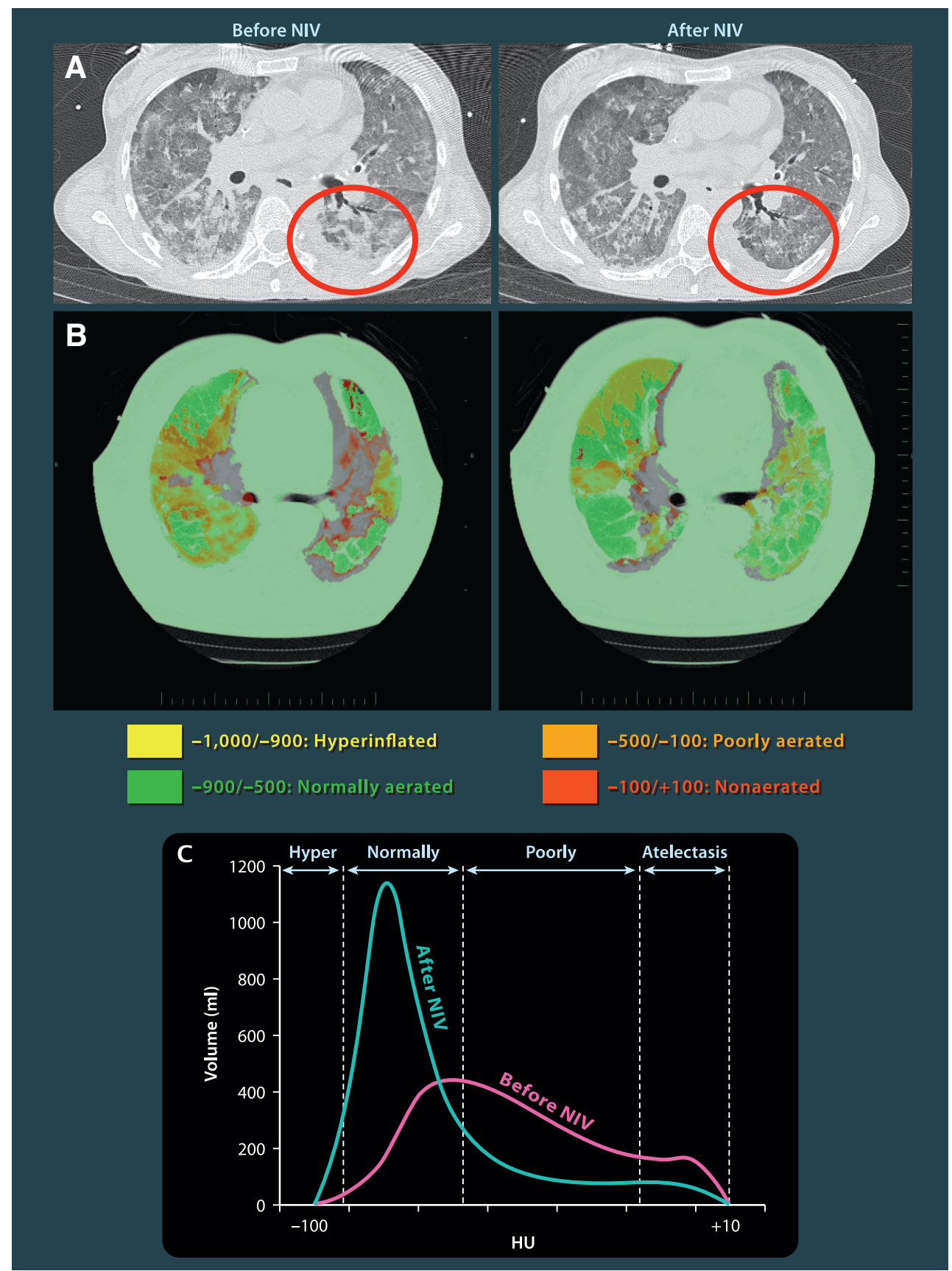

Fig. 2. Effects of postoperative noninvasive ventilation (NIV) on computed tomography (CT) lung volumes in patients with acute respiratory failure after abdominal surgery. (A) Representative CT slices of the lung obtained before NIV in spontaneous breathing (left panel) and after 30 min of NIV (PSV $15 \mathrm{~cm} \mathrm{H}_{2} \mathrm{O}$ and PEEP $5 \mathrm{~cm} \mathrm{H}_{2} \mathrm{O}$ ) (right panel). (B) A color encoding analysis is applied for both CT images obtained before (left panel) and after 30 min of NIV (right panel). Nonaerated voxels (CT attenuation between -100 and +100 Hounsfield Units [HU]) were colored in red, poorly aerated voxels (CT attenuation between -500 and $-100 \mathrm{HU}$ ) in orange, and normally aerated voxels (CT attenuation between -500 and $-900 \mathrm{HU}$ ) in green. Overinflated voxels (CT attenuations between -900 and $-1,000 \mathrm{HU}$ ) were colored in yellow. NIV induced alveolar recruitment as shown by the decrease in poorly (orange) and nonaerated (red) lung regions and an increase in normally aerated lung parenchyma (green). (C) Volumetric quantification of lung aeration and collapse. Histograms show the normalized lung volume for HU ranging from $-1,000$ to 100 . aeration categories (hyperinflated $-1,000$ and $-900 \mathrm{HU}$, normally aerated -900 and -500 , poorly aerated -500 and $-100 \mathrm{HU}$, nonaerated or atelectasis -100 and $+100 \mathrm{HU}$ ). The red curve was obtained before NIV and the yellow curve was obtained after NIV. Note that the curve obtained after NIV showed a decrease in poorly and nonaerated lung regions and an increase in normally aerated lung parenchyma.

monary disease). Clinical improvements caused via an improved cardiac function are sometimes difficult to distinguish from the pulmonary effects of CPAP in postoperative period.
PSV is a ventilatory mode in which the patient's spontaneous inspiratory effort triggers the ventilator to provide a variable flow of gas that increases until airway pressure reaches a selected level. Thus, during each spontaneous in- 
spiration, the patient receives a pressure-supported breath. Once the selected airway pressure is achieved, the patients can continue to breathe until their inspiratory flow rate drops below a threshold level in the absence of leaks (usually a fixed level at $25 \%$ of the peak flow). Thus, the tidal volume achieved depends on patient's respiratory compliance and the patient's own effort added to that of the ventilator's inspiratory pressure, which can be capped at a relatively low level. The main singularity of PSV mode is that the patients control not only their respiratory rate but also their inspiratory and expiratory times. PSV has been widely used as partial ventilatory support to improve patient-ventilator synchrony and then the comfort. Ventilator settings should be adjusted to provide the lowest inspiratory pressures or volumes needed to produce improved patient comfort (a decrease in respiratory rate and respiratory muscle unloading) and gas exchange.

We can consider that CPAP used alone essentially helps to provide satisfactory gas exchange through changes in ventilation/perfusion ratio and increase in oxygen partial alveolar pressure. PSV above PEEP, as compared with CPAP, provides a better physiologic response in terms of muscle unloading and dyspnea relief. PSV + PEEP ensures alveolar ventilation, whereas CPAP alone does not. Then, it is difficult to recommend a single combination PSV/PEEP for all patients, and probably an individual titration should be performed to find the best NIV setting to reduce dyspnea, unload respiratory muscles, and increase oxygenation.

Initially, the clinical experience reported in postsurgical patients was limited to the use of CPAP alone. Moreover, in these studies, ${ }^{15} \mathrm{CPAP}$ was used to prevent ARF after surgery (prophylactic use, i.e., immediately after extubation, not waiting for patients to develop respiratory distress) but not to treat ARF once it developed (curative use). ${ }^{15}$ However, studies of ARF in the postoperative setting have shown favorable results for both NIV practice PSV + PEEP and CPAP.

\section{NIV Application}

Postoperative NIV can be proposed in two ways (fig. 1). The first is a preventive or "prophylactic" application to prevent postoperative ARF from developing in patients at risk (elderly, obese, chronic obstructive pulmonary disease, and heart disease) and the second consists of a "curative" application, once ARF occurs, to alleviate respiratory failure while avoiding tracheal intubation, a cause of increased morbidity. Nevertheless, NIV (PSV + PEEP or CPAP) should never be initiated in confused patients, those unable to cooperate, or with hemodynamic instability. Moreover, tracheal intubation should never be delayed if respiratory status worsened despite CPAP or PSV + PEEP ventilatory support. Two multicenter randomized studies ${ }^{16,17}$ reported that NIV is not effective for the management of postextubation respiratory failure in nonselected patients (curative use), and delayed reintubation may increase mortality. ${ }^{16}$ In contrast, randomized studies ${ }^{5,18}$ showed that the early use of NIV can prevent respiratory failure after extubation and decrease the need for reintubation in selected patients considered at risk for postextubation respiratory failure (preventive use).

\section{How to Set NIV and Duration of Trial}

NIV works best in patients relaxed and prepared. CPAP pressures of $7-10 \mathrm{~cm} \mathrm{H} \mathrm{H}_{2} \mathrm{O}$ are required to keep tracheal pressure positive during the entire respiratory cycle and to consistently improve gas exchange. These CPAP pressures are safe, and no adverse hemodynamic effects were observed. In PSV + PEEP, patient comfort and interface acceptance may be gained by starting with PEEP alone and then slowly increasing the PSV level once the mask is applied (fig. 3). We recommend starting with a PSV of $3-5 \mathrm{~cm} \mathrm{H}_{2} \mathrm{O}$ and increasing in increments of $2 \mathrm{~cm} \mathrm{H} \mathrm{H}_{2} \mathrm{O}$ to achieve a $6-10 \mathrm{ml} / \mathrm{kg}$ expiratory tidal volume, a decrease in the patient's respiratory rate, and a comfort improvement ${ }^{11}$ (fig. 3). The PEEP is started at $3-5 \mathrm{~cm} \mathrm{H}_{2} \mathrm{O}$ and increased as needed to improve oxygenation without adverse hemodynamic effects up to 10 $\mathrm{cm} \mathrm{H}_{2} \mathrm{O}$. The insufflation pressure (PSV + PEEP level) applied should be less than $25 \mathrm{~cm} \mathrm{H}_{2} \mathrm{O}$. These setting recommendations are based solely on clinical experience without any formal data to support the superiority of one technique over another. ${ }^{6}$ A surgical complication arises in nearly half the cases of ARF. The treatment is usually reintervention, management of ARF is only symptomatic, and there is no reason to use NIV to avoid intubation because the patient requires intubation for anesthesia.

Evidence to guide duration of NIV trial is lacking; hence, the recommendations are based largely on practitioner experience. In postoperative area, we recommended "sequential" use wherein periods of use alternate with lengthy ventilatorfree periods, and total daily use ranges between 3 and $12 \mathrm{~h}$ depending on the type of application (curative or prophylactic use). In our practices, ${ }^{11}$ during the first $24 \mathrm{~h}$, for the majority of the patients, NIV was applied for approximately $30-45 \mathrm{~min}$ at 2- to 4-h intervals (prophylactic), depending on the patient's clinical condition. Some patients were treated during the initial period with NIV for 60-90 min at 2- to 3-h intervals (range, 8-12 h/day; curative). Between the periods of NIV, the patients breathed through a Venturi mask. The length of NIV cycles was progressively reduced and was withdrawn completely, as blood gas values and clinical condition improved.

\section{Ventilators}

Both intensive care unit (ICU) and portable ventilators can be used for postoperative NIV, and to date, no study has demonstrated superiority of one type over the other. ${ }^{19}$ However, devices using a common inspiratory and expiratory line can cause rebreathing of exhaled gases and persistent hypercapnia. ${ }^{20}$ ICU ventilators were originally designed to ventilate intubated patients, that is, with minimal or no leaks, and fare less well in their presence. ${ }^{19}$ Because, ICU ventilators have been increasingly used for NIV over the years and the presence of leaks at the patient-ventilator interface interferes 


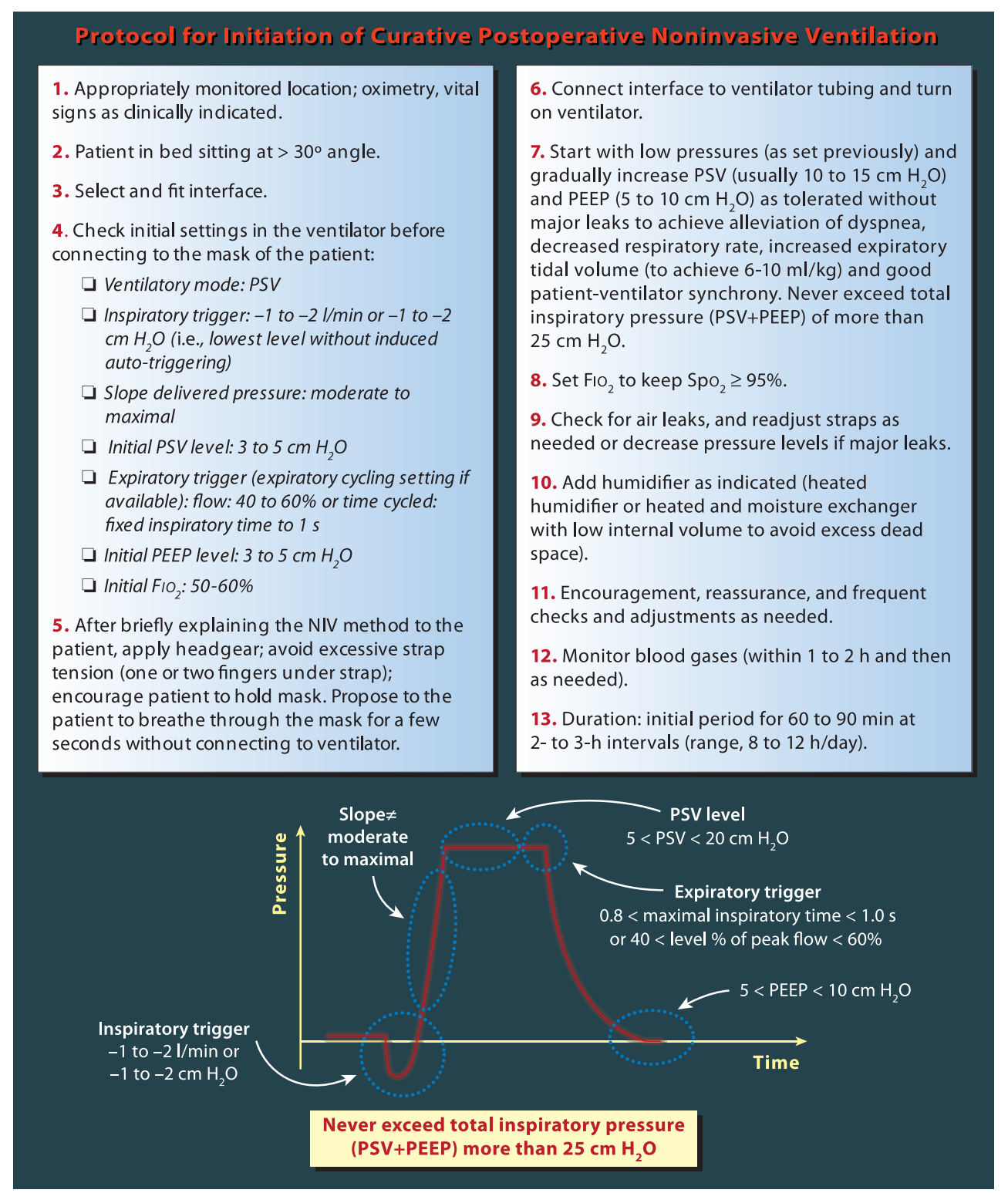

Fig. 3. Protocol for initiation of curative postoperative noninvasive ventilation (NIV). PSV = pressure support ventilation; PEEP = positive end expiratory pressure. $\mathrm{FlO}_{2}=$ fraction of inspired oxygen; $\mathrm{SpO}_{2}=$ pulsated oximetry.

with several key ventilator functions, manufacturers offer in the recent generations of ICU ventilators NIV-specific mode dedicated to preventing these problems. ${ }^{19}$ Larger leaks from around the mouth are irritating to the patient and trigger insensitivity and prolonged expiratory time, ultimately resulting in patient-ventilator asynchrony. The tight fitting of a properly selected NIV mask reduces the magnitude of leaks (usually ranged between 20 and 40\%), but this measure alone often proves insufficient and can be limited by skin complications and patient discomfort. The majority of ventilators using PSV mode have a cycling mechanism based on the achievement of a preset flow threshold (i.e., $25 \%$ of peak inspiratory flow), which may be not functional in the presence of leaks. In the most recent ventilator generations, the preset flow threshold of cycling and the inspiratory time can be set by a user to avoid prolonged inspiratory time. Other alternatives to provide a better patient-ventilator interaction (except optimize the interface, see next section) are to use a preset limited inspiratory time or to use a time-cycled rather than a flow-cycled expiratory trigger, by using pressure-controlled ventilation mode, which is pressure limited and time cycled. The new NIV modes (or options) provide PSV with leak compensation, which aims to minimize the impact of leaks on key ventilator functions (mainly inspiratory and expiratory triggers). ${ }^{19}$ The leak compensation mechanism varied between ventilators, and it depends of the software developed by each manufacturer. ${ }^{19}$ Briefly, the rationale of NIV leak compensation consists of recording continuous leaks evaluated by measuring the difference between inspiratory and expiratory tidal volumes. The microprocessor of ventilator already assesses inspiratory and expiratory flow (then volume) and pressure continuously and it retains these informations in memory. Then, to compensate for a significant leak, the ventilator will increase peak inspiratory flow 
rates without prolonged inspiratory time, which is counterproductive by inducing patient-ventilator asynchrony. Modern pressure ventilators can compensate for very large leaks up to $180 \mathrm{l} / \mathrm{min}$.

\section{Interfaces}

The main difference between invasive and NIV is that with the latter technique, gas is delivered to the airway via an interface (nasal, facial mask, or helmet) rather than an invasive tube (endotracheal or tracheotomy) with mandatory variable leaks. An interface that fits properly is crucial in minimizing air leaks and maximizing NIV efficiency. Recommendations for evaluating different sizes and types of masks at the bedside are important to select the best fit for each patient. The first few minutes should be used to fit the mask and familiarize the patient with the equipment. Patients may feel claustrophobic, especially when increasing respiratory drive and when difficult breathing is present. NIV is tolerated best when pressures are increased gradually, as the work of breathing and respiratory drive eases (fig. 3). The choice of interface is very important when applying NIV and even more so in the presence of a gastric tube. Indeed, if the patient's morphology and the gastric tube lead to increased leaks, the medical team applying NIV must dispose of several interfaces to trial for each patient to choose one with minimal leakage. To date, there is no evidence to support the use of particular patient interface devices in surgical context. Then, practitioners should try different mask sizes and types in an effort to enhance patient comfort.

\section{Contraindications and Limits}

Patient cooperation without deteriorating mental status, absence of hemodynamic instability, and ability to protect airways are crucial to the application and the success of NIV. The relative and absolute contraindications of NIV use are reported in table 1 . When NIV is applied, the patients must be monitored and attention should be given to their comfort, level of dyspnea, respiratory rate, and oxygen saturation. Patients must be watched for signs of ventilator asynchrony, mask intolerance, serious air leaks, gastric distension, ocular drying, and facial skin breakdown, especially at the nasal bridge.

\section{Problems Related with Digestive Tube and Its Interrelation with NIV}

Upper digestive stitching requires great prudence with early postoperative NIV. Historically, NIV was contraindicated for upper digestive anastomoses. In fact, there is a risk of intradigestive air insufflation when high insufflation pressures are applied (PSV + PEEP $>25 \mathrm{~cm} \mathrm{H}_{2} \mathrm{O}$ ). ${ }^{6}$ However, the risk of stitch leakage due to nonoptimal NIV settings may be avoided by preferring CPAP over PSV. If PSV use is needed, the PSV level must be maintained below $6-8 \mathrm{~cm}$ $\mathrm{H}_{2} \mathrm{O}$. Moreover, compared with NIV using PSV + PEEP, CPAP is easier to perform especially outside ICU and/or
Table 1. Contraindications for the Use of Postoperative Noninvasive Ventilation (NIV)

\section{Absolute}

- Cardiac or respiratory arrest

- Multiple organ failure

- Severe agitation or encephalopathy

- Copious secretions

- Uncontrolled vomiting

- Inability to protect airway

- Severe upper gastrointestinal bleeding or hemoptysis

- Immediate endotracheal intubation necessary (except for preoxygenation NIV)

- Facial trauma

- Hemodynamic instability or unstable cardiac arrhythmia

\section{Relative}

- Mildly decreased level of consciousness

- Progressive severe respiratory failure

- Uncooperative patient who can be calmed or comforted

postanesthesia care. One limiting factor in PSV + PEEP implementation might be operator skill. It is known that the more experienced the operator and/or the team, the higher the success rate of PSV + PEEP. However, in some patients, CPAP and PSV + PEEP may be applied alternatively in aim to improve tolerance and/or efficiency.

The presence of a nasogastric tube after digestive surgery may increase leaks around the facial mask during NIV. Some manufacturers have proposed specific device to limit leaks around the mask with nasogastric tube. These systems should be evaluated in clinical practices. It is recommended to keep the gastric tube on a bag rather than in aspiration to detect deleterious gastric insufflation. In case of intragastric air insufflation, the bag will rapidly inflate, indicating that the NIV settings, and eventually the use of NIV itself, need to be reevaluated.

The optimal location for patients receiving NIV is ICU or recovery room. It depends on the capacity for adequate monitoring, staff skill and experience in explaining the procedure, their knowledge of the equipment used, and awareness of potential complications.

\section{Results Obtained in Different Type of Surgery Using Preventive or Curative NIV}

\section{Cardiac Surgery}

Preventive NIV. The restrictive syndrome consecutive to cardiac surgery is generally less severe than that observed after 
thoracic or abdominal surgery. ${ }^{1}$ However, the incidence of diaphragm dysfunction is higher. ${ }^{1}$ Early studies mainly compared CPAP with standard treatment (oxygen + physiotherapy). Most of these studies reported improved oxygenation and ventilation parameters. None of these studies found any reduction in the incidence of atelectasis in the groups treated by NIV, in fact mostly CPAP, except for Jousela et al. ${ }^{21}$ Gust et al. ${ }^{14}$ obtained a reduction in extravascular lung water when NIV was applied with CPAP alone or with PSV (PSV + PEEP). Matte et al., ${ }^{22}$ in a study including 96 patients, evaluated "preventive" NIV in the first 2 days after surgery. Various strategies were compared in three randomized groups. The first group received $1 \mathrm{~h}$ of NIV with two pressure levels every $3 \mathrm{~h}$ with an average assistance level of $12 \mathrm{~cm} \mathrm{H}_{2} \mathrm{O}$ of PSV and $5 \mathrm{~cm} \mathrm{H}_{2} \mathrm{O}$ of PEEP. The second group received a 1-h session of CPAP at $5 \mathrm{~cm} \mathrm{H}_{2} \mathrm{O}$ every $3 \mathrm{~h}$, and a third group had 20 min of incentive spirometry every $2 \mathrm{~h}$. Using NIV whether at one or two pressure levels permitted improved oxygenation and a lower reduction of lung volumes. However, atelectasis incidence was similar (12-15\%) in all three groups. ${ }^{22}$ Pasquina et al. ${ }^{23}$ compared the effect of systematic application of a 30-min trial of $5 \mathrm{~cm} \mathrm{H}_{2} \mathrm{O}$ CPAP with NIV (PSV 10 and PEEP 5) in two groups of 75 patients. The NIV group had improved radiologic scores (meaning less marked atelectasis) on standard chest radiograph. There was no significant difference in oxygenation parameters. ${ }^{23}$ Recently, Zarbock et al. ${ }^{24}$ reported in a prospective randomized study included 500 patients scheduled for elective cardiac surgery, the interest of prophylactic nasal CPAP of 10 $\mathrm{cm} \mathrm{H}_{2} \mathrm{O}$ (study) for at least $6 \mathrm{~h}$ /day after surgery in comparison with standard treatment (control) including $10 \mathrm{~min}$ of intermittent nasal CPAP at $10 \mathrm{~cm} \mathrm{H}_{2} \mathrm{O}$ every $4 \mathrm{~h}$. In the study group, CPAP improved arterial oxygenation, reduced the incidence of pulmonary complications including pneumonia and reintubation rate, and reduced readmission rate to ICU or intermediate care unit.

Curative NIV. To our knowledge, at the time of writing, no study has been published concerning the effect of curative NIV in patients who have developed ARF after cardiac surgery.

\section{Thoracic Surgery}

Preventive NIV. In a physiologic study, Aguilo et al. ${ }^{25}$ studied the effects of a 1-h NIV trial after pulmonary resection in 10 patients. NIV was applied without any complications due to the technique and allowed improved oxygenation without increasing leaks around thoracic drains in the study group compared with a control group who did not receive NIV. ${ }^{25}$ Perrin et al. ${ }^{26}$ reported in a prospective randomized clinical trial the benefits of NIV administered pre- and postoperatively. Patients were required to follow standard treatment without or with NIV during 7 days at home before surgery and during 3 days postoperatively. In this study, ${ }^{26} 2 \mathrm{~h}$ after surgery, oxygenation and lung volumes values were significantly better in the NIV group. On days 1, 2, and 3, oxygenation was significantly improved in the NIV group. The hospital stay was significantly longer in the control group than in the NIV group. This first prospective randomized study ${ }^{26}$ showed that prophylactic use of NIV in a pre- and postoperative manner significantly reduces pulmonary dysfunction after lung resection.

Curative NIV. In an observational study, Rocco et al. ${ }^{27}$ described their experience of NIV after lung transplant in 21 patients who developed ARF. Tolerance of NIV was good for all patients.

Eighteen of the 21 patients treated were able to avoid reintubation. ${ }^{27}$ In a prospective randomized study including 24 patients in each group, Auriant et al. ${ }^{9}$ showed the efficiency of NIV in ARF after lung resection. In this trial, ${ }^{9} \mathrm{NIV}$ was delivered by a nasal mask using a single circuit ventilator and compared with standard treatment (oxygen + physiotherapy + bronchodilators), reducing the need for invasive mechanical ventilation $(21 \%$ vs. $50 \%)$ and mortality $(13 \%$ vs. $38 \%$ ). Recently, Lefebvre et al. ${ }^{28}$ confirmed in an observational prospective survey the feasibility and efficacy of early NIV in ARF after lung resection. During a 4-yr period, among 690 patients at risk of severe complications after lung resection, $16 \%$ experienced ARF, which was initially managed by NIV. The overall success rate of NIV was $85 \%$.

\section{Abdominal Surgery}

Preventive NIV. Hypoxemia complicates the recovery of $30-$ $50 \%$ of patients after abdominal surgery, even among those undergoing uneventful procedures. Stock et al. ${ }^{29}$ showed that applying a CPAP in patients having cholecystectomy by laparotomy permitted a significant improvement in number of atelectasis compared with treatment by incentive spirometry. After bariatric surgery (gastroplasty) for morbid obesity, Joris et al. ${ }^{30}$ demonstrated a significant reduction of the restrictive syndrome and significant improvement in oxygenation evaluated by oximetry $\left(\mathrm{SpO}_{2}\right)$ with NIV applied for two-thirds of the first postoperative $24 \mathrm{~h}$. Compared with the control group, forced vital capacity was improved significantly only with a moderately high PSV level of $12 \mathrm{~cm} \mathrm{H}_{2} \mathrm{O}$, because another group treated with a PSV level of $8 \mathrm{~cm} \mathrm{H}_{2} \mathrm{O}$ did not have a significant improvement of functional residual capacity. This finding remains important today, given the sharp increase in the rate of obesity surgery nationwide. ${ }^{30}$ Kindgen-Milles et $a l^{31}$ studied the effect of a systematic CPAP of $10 \mathrm{~cm} \mathrm{H}_{2} \mathrm{O}$ for 12-24 h a day after thoracoabdominal surgery (aneurysm of thoracoabdominal aorta cure). The group of patients receiving CPAP had significantly improved oxygenation and a shorter ICU and hospital stay than those in the control group. A large Italian study ${ }^{10}$ was stopped early because of improvements in intubation related to CPAP therapy in hypoxemic patients after abdominal surgery. This randomized study ${ }^{10}$ included 209 patients in two groups: one group received CPAP and a control group receiving oxygen via a facial mask. The patients receiving CPAP had significantly lower intubation, pneumonia, and sepsis rates than the control group. ${ }^{10}$

Curative NIV. Patients suffering from postoperative ARF have been included among other types of patients in studies 
evaluating NIV to treat ARF of multiple causes. ${ }^{6}$ In these studies, no comparison has been made between patients presenting with ARF of medical causes and those with postoperative ARF, probably because of the heterogeneity and small numbers of patients included. Varon et al. ${ }^{32}$ reported the feasibility of NIV in postoperative ARF in cancer patients (25 digestive, 15 urogenital, and 6 lung). Intubation was avoided in $70 \%$ of included patients in this study. ${ }^{32}$ Kindgen-Milles et al., ${ }^{33}$ in a noncontrolled prospective study, showed that CPAP rapidly improved oxygenation and avoided intubation in 18 of 20 patients treated after abdominal and/or thoracic surgery. Jaber et al. ${ }^{11}$ reported in an observational study their experience over a 2-yr period using NIV in 72 patients with severe ARF after digestive surgery. In this prospective trial, ${ }^{11}$ intubation was avoided in $66 \%$ of patients. This study ${ }^{11}$ demonstrated feasibility, good tolerance, and safety of NIV for the treatment of ARF after digestive surgery. More severe initial hypoxemia and lower improvement of $\mathrm{PaCO}_{2}$ after NIV were predictive of NIV failure. ${ }^{11}$ The results obtained in the study by Jaber et al. was confirmed by a recent study that included 72 patients who developed ARF after abdominal surgery and 42 patients avoided intubation $(58 \%) .{ }^{34}$ Conti et al. ${ }^{35}$ in a match-controlled study compared the efficacy of NIV delivered by a helmet interface and a facial mask in patients with ARF after abdominal surgery. These authors reported an NIV success rate of $80 \%$ in the helmet group and of $52 \%$ in the facial mask group. ${ }^{35}$ Antonelli et al. ${ }^{36}$ showed in a controlled randomized trial that in organ transplant recipients with hypoxemic ARF, NIV reduced the rate of intubation, the incidence of fatal complications, and ICU mortality compared with the provision of supplemental oxygenation alone. More recently, Michelet et al. ${ }^{37}$ compared in a case-control study the efficacy of NIV with conventional treatment in 36 patients who developed postoperative ARF after planned esophagectomy. They showed that the use of NIV was associated with a lower intubation rate, frequency of acute respiratory distress syndrome, anastomotic leakage, and a reduction in ICU length of stay.

\section{Conclusion}

Regardless of the presence of complications, thoracic and/or abdominal surgery necessarily and profoundly alters the respiratory system for long periods. Mechanical ventilation through an endotracheal tube may be responsible for extra morbidity (barotraumatic complications, nosocomial pneumonia, and others). During the past decade, NIV has proven to be an effective strategy to reduce intubation rates, nosocomial infections, ICU and hospital lengths of stay, and morbidity and mortality in patients with either hypercapnic or nonhypercapnic ARF. However, before initiating NIV in postoperative period in patients with ARF, a surgical complication (anastomoses leakage, intraabdominal sepsis, and others) should be eliminated and treated. Then, if patients are cooperative and able to protect their airway, NIV can be initiated regardless of the safety procedures and respect of contraindications. The application of postoperative NIV by a trained and experienced ICU team, with careful patient selection, should optimize patient outcome.

The authors are grateful to Patrick McSweeny (Biomedical Engineer, Fisher-Paykell, Courtaboeuf, France) for his English editing.

\section{References}

1. Warner M: Preventing postoperative pulmonary complications. The role of the anesthesiologist AnESTHEsiology 2000; 92:1467-72

2. Simonneau G, Vivien A, Sartene R, Kunstlinger F, Samii K, Noviant Y, Duroux P: Diaphragm dysfunction induced by upper abdominal surgery. Role of postoperative pain. Am Rev Respir Dis 1983; 128:899-903

3. Duggan M, Kavanagh BP: Pulmonary atelectasis: A pathogenic perioperative entity. AnESTHESIOLOGY 2005; 102 $838-54$

4. Smetana G: Preoperative pulmonary evaluation. N Engl J Med 1999; 340:937-45

5. Nava S, Gregoretti C, Fanfulla F, Squadrone E, Grassi M, Carlucci A, Beltrame F, Navalesi P: Noninvasive ventilation to prevent respiratory failure after extubation in high-risk patients. Crit Care Med 2005; 33:2465-70

6. International consensus conferences in intensive care medicine. Noninvasive positive pressure ventilation in acute respiratory failure. Am J Respir Crit Care Med 2001; 163: 283-91

7. Baillard C, Fosse JP, Sebbane M, Chanques G, Vincent F, Courouble P, Cohen Y, Eledjam JJ, Adnet F, Jaber S: Noninvasive ventilation improves preoxygenation before intubation of hypoxic patients. Am J Respir Crit Care Med 2006; 174:171-7

8. Delay JM, Sebbane M, Jung B, Nocca D, Verzilli D, Pouzeratte Y, Kamel ME, Fabre JM, Eledjam JJ, Jaber S: The effectiveness of noninvasive positive pressure ventilation to enhance preoxygenation in morbidly obese patients: A randomized controlled study. Anesth Analg 2008; 107: 1707-13

9. Auriant I, Jallot A, Hervé P, Cerrina J, Le Roy Ladurie F, Lamet Fournier J, Lescot B, Parquin F: Noninvasive ventilation reduces mortality in acute respiratory failure following Lung resection. Am J Respir Crit Care Med 2001; 164:1231-5

10. Squadrone V, Coha M, Cerutti E, Schellino M, Biolino P Occella P, Belloni G, Vilianis G, Fiore G, Cavallo F, Ranieri V, (PICUN) PICUN: Continuous positive airway pressure for treatment of postoperative hypoxemia: A randomized controlled trial. JAMA 2005; 293:589-95

11. Jaber S, Delay J, Sebbane M, Chanques G, Jacquet E, Souche B, Perrigault P, Eledjam J: Outcomes of patients with acute respiratory failure after abdominal surgery treated with noninvasive positive-pressure ventilation. Chest 2005; 128:2688-95

12. Chanques G, Jaber S, Delay J, Lefrant J, Perrigault P, Eledjam J: Phoning study about postoperative practice and application of non-invasive ventilation. Ann Fr Anesth Reanim 2003; $22: 879-85$

13. Battisti A, Michotte J, Tassaux D, van Gessel E, Jolliet P. Non-invasive ventilation in the recovery room for postoperative respiratory failure: A feasibility study. Swiss Med Wkly 2005; 135:339-43

14. Gust R, Gottschalk A, Schmidt H, Bottiger B, Bohrer H Martin E: Effects of continuous (CPAP) and bi-level positive airway pressure (BiPAP) on extravascular lung water after extubation of the trachea in patients following coronary artery bypass grafting. Intensive Care Med 1996 22:1345-50

15. Ferreyra GP, Baussano I, Squadrone V, Richiardi L, Marchiaro G, Del Sorbo L, Mascia L, Merletti F, Ranieri VM: 
Continuous positive airway pressure for treatment of respiratory complications after abdominal surgery: A systematic review and meta-analysis. Ann Surg 2008; 247:617-26

16. Esteban A, Frutos-Vivar F, Ferguson N, Arabi Y, Apezteguía C, González M, Epstein S, Hill N, Nava S, Soares M, D'Empaire G, Alí I, Anzueto A: Noninvasive positive-pressure ventilation for respiratory failure after extubation. N Engl J Med 2004; 350:2452-60

17. Keenan S, Powers C, McCormack D, Block G: Noninvasive positive-pressure ventilation for postextubation respiratory distress: A randomized controlled trial. JAMA 2002; $287: 3238-44$

18. Ferrer M, Valencia M, Nicolas JM, Bernadich O, Badia JR, Torres A: Early noninvasive ventilation averts extubation failure in patients at risk: A randomized trial. Am J Respir Crit Care Med 2006; 173:164-70

19. Vignaux L, Tassaux D, Jolliet P: Performance of noninvasive ventilation modes on ICU ventilators during pressure support: A bench model study. Intensive Care Med 2007; 33:1444-51

20. Lofaso F, Brochard L, Hang T, Lorino H, Harf A, Isabey D: Home versus intensive care pressure support devices: Experimental and clinical comparison. Am J Respir Crit Care Med 1996; 153:1591-9

21. Jousela I, Rasanen J, Verkkala K, Lamminen A, Makelainen A, Nikki P: Continuous positive airway pressure by mask in patients after coronary surgery. Acta Anaesthesiol Scand 1994; 38:311-6

22. Matte $P$, Jacquet $M$, Vandyck $M$, Goenen $M$ : Effects of conventional physiotherapy, continuous positive airway pressure and non-invasive ventilatory support with bilevel positive airway pressure after coronary artery bypass grafting. Acta Anaesthesiol Scand 2000; 44:75-81

23. Pasquina P, Merlani P, Granier J, Ricou B: Continuous positive airway pressure versus noninvasive pressure support ventilation to treat atelectasis after cardiac surgery. Anesth Analg 2004; 99:1001-8

24. Zarbock A, Mueller E, Netzer S, Gabriel A, Feindt P, Kindgen-Milles D: Prophylactic nasal continuous positive airway pressure following cardiac surgery protects from postoperative pulmonary complications: A prospective, randomized, controlled trial in 500 patients. Chest 2009; 135:1252-9

25. Aguilo R, Togores B, Pons S, Mateu R, Barbé F, Agusti A: Noninvasive ventilatory support after lung resectional surgery. Chest 1997; 112:117-21

26. Perrin C, Jullien V, Vénissac N, Berthier F, Padovani B, Guillot F, Coussement A, Mouroux J: Prophylactic use of noninvasive ventilation in patients undergoing lung resectional surgery. Respir Med 2007; 101:1572-8

27. Rocco M, Conti G, Antonelli M, Bufi M, Costa MG, Alampi
D, Ruberto F, Stazi GV, Pietropaoli A: Non-invasive pressure support ventilation in patients with acute respiratory failure after bilateral lung transplantation. Intensive Care Med 2001; 27:1622-6

28. Lefebvre A, Lorut C, Alifano M, Dermine H, Roche N, Gauzit R, Regnard JF, Huchon G, Rabbat A: Noninvasive ventilation for acute respiratory failure after lung resection: An observational study. Intensive Care Med 2009; 35:663-70

29. Stock M, Downs J, Gauer P, Alster J, Imrey P: Prevention of postoperative pulmonary complications with CPAP, incentive spirometry, and conservative therapy. Chest 1985 $87: 151-7$

30. Joris J, Sottiaux T, Chiche J, Desaive C, Lamy M: Effect of bi-level positive airway pressure (BiPAP) on the postoperative pulmonary restrictive syndrome in obese patients undergoing gastroplasty. Chest 1997; 111:665-70

31. Kindgen-Milles D, Muller E, Buhl R, Bohner H, Ritter D, Sandmann W, Tarnow J: Nasal-continuous positive airway pressure reduces pulmonary morbidity and length of hospital stay following thoracoabdominal aortic surgery. Chest 2005; 128:821-8

32. Varon J, Walsh G, Fromm RJ: Feasibility of noninvasive mechanical ventilation in the treatment of acute respiratory failure in postoperative cancer patients. J Crit Care $1998 ; 13: 55-7$

33. Kindgen-Milles D, Buhl R, Gabriel A, Bohner H, Muller E: Nasal continuous positive airway pressure: A method to avoid endotracheal reintubation in postoperative high-risk patients with severe nonhypercapnic oxygenation failure. Chest 2000; 117:1106-11

34. Wallet F, Scoeffler M, Reynaud M, Duperret S, Workineh S, Viale $\mathrm{J}$ : Factors associated with noninvasive ventilation failure in post operative acute respiratory insufficiency: An observational study. Eur J Anaesthesiol (E-pub ahead of print June 15, 2009.) doi: 10.1097/EJA.0b013e32832dbd49

35. Conti G, Cavaliere F, Costa R, Craba A, Cartaci S, Festa V, Proietti R, Antonelli M: Noninvasive positive pressure ventilation with different interfaces in patients with respiratory failure after abdominal surgery: A match-control study. Respir Care 2007; 52:1463-71

36. Antonelli M, Conti G, Bufi M, Costa M, Lappa A, Rocco M, Gasparetto A, Meduri G: Noninvasive ventilation for treat ment of acute respiratory failure in patients undergoing solid organ transplantation: A randomized trial. JAMA 2000; 283:235-41

37. Michelet P, D'Journo XB, Seinaye F, Forel JM, Papazian L, Thomas P: Non-invasive ventilation for treatment of postoperative respiratory failure after oesophagectomy. $\mathrm{Br}$ Surg 2009; 96:54-60 